\title{
Biological reduction of iron to the elemental state from ochre deposits of Skelton Beck in Northeast England
}

\section{Pattanathu K. S. M. Rahman * and Suvechhya Bastola}

Technology Futures Institute, School of Science and Engineering, Teesside University, Middlesbrough, UK

\section{Edited by:}

Nicolas Kalogerakis, Technical

University of Crete, Greece

\section{Reviewed by:}

Kostas A. Komnitsas, Technical University Crete, Greece

Nymphodora Papassiopi, National

Technical University of Athens,

Greece

\section{*Correspondence:}

Pattanathu K. S. M. Rahman,

Technology Futures Institute, School

of Science and Engineering,

Teesside University, Borough Rd.,

Tees Valley, Middlesbrough

TS1 3BA, UK

e-mail:p.rahman@tees.ac.uk
Ochre, consequence of acid mine drainage (AMD), is iron oxides-rich soil pigments that can be found in the water drainage from historic base metal and coal mines. The anaerobic strains of Geobacter sulfurreducens and Shewanella denitrificans were used for the microbial reduction of iron from samples of ochre collected from Skelton Beck (Saltburn Orange River, NZ 66738 21588) in Northeast England. The aim of the research was to determine the ability of the two anaerobic bacteria to reduce the iron present in ochre and to determine the rate of the reduction process. The physico-chemical changes in the ochre sample after the microbial reduction process were observed by the production of zero-valent iron which was later confirmed by the detection of elemental $\mathrm{Fe}$ in XRD spectrum. The X-Ray fluorescence (XRF) results revealed that 69.16 and $84.82 \%$ of iron oxide can be reduced using $G$. sulfurreducens and $S$. denitrificans respectively after 8 days of incubation. These results could provide the basis for the development of a biohydrometallurgical process for the production of elemental iron from ochre sediments.

Keywords: iron, ochre, mine water treatment, Geobacter sulfurreducens, Shewanella denitrificans

\section{INTRODUCTION}

Water seepage from old ironstone mine workings into Skelton Beck is caused by rising ground-water levels from the old Longacre Pit in Skelton, which is choked with iron ochre. The iron deposits have colored the beck red and threaten wildlife. Government agencies worldwide often face challenges toward remediation of water contaminated by historical mining activities (Mayes et al., 2009).

Acid Mine Drainage (AMD) is one of the most challenging environmental problems faced today due to historic mine activities. Looking at the mining history it has been stated that a total of about 1150 million tons of heavy metals have been mined since the Stone Age (Sheoran and Sheoran, 2006; Simpson et al., 2014). The typical characteristic of AMD is the significantly low $\mathrm{pH}$ and high concentration of heavy metals (Engleman and McDiffett, 1996). This problem results from the microbial oxidation of iron pyrite in the presence of water and air generating acidic leachates containing toxic metal ions and sulfates (Mohan and Chander, 2006).

The oxidation of iron disulfides (pyrite) occurs in the beginning, this oxidation reaction may release ferrous iron, sulfate and $\mathrm{H}^{+}$in the aqueous solution (Reaction 1). Ferrous iron is simultaneously oxidized to the ferric form (Reaction 2 ), which is hydrolyzed and ferric hydroxide is generated.

$$
\begin{gathered}
2 \mathrm{FeS}_{2}(\text { Pyrite })+7 \mathrm{O}_{2}+2 \mathrm{H}_{2} \mathrm{O} \rightarrow 2 \mathrm{Fe}^{2+} \text { (ferrous iron) } \\
+4 \mathrm{SO}_{4}^{2}(\text { Sulfate })+4 \mathrm{H}^{+}(\text {acid }) \\
4 \mathrm{Fe}^{2+}+\mathrm{O}_{2}+4 \mathrm{H}^{+} \rightarrow 4 \mathrm{Fe}^{3+}+2 \mathrm{H}_{2} \mathrm{O}
\end{gathered}
$$

Komnitsas and Pooley (1990) reported acceleration of pyrite oxidation by bacterially generated ferric iron. Other microorganisms like Thiobacillus ferrooxidans derive energy from the oxidation of ferrous to ferric iron (Cheng et al., 2009).

$$
\mathrm{FeS}_{2}+14 \mathrm{Fe}^{3+}+8 \mathrm{H}_{2} \mathrm{O} \rightarrow 15 \mathrm{Fe}^{2+}+2 \mathrm{SO}_{4}^{2-}+16 \mathrm{H}^{+}
$$

Thus, it can be observed that eventually $\mathrm{SO}_{4}^{2-}$ concentration is increased (Reaction 3) and the $\mathrm{pH}$ is decreased due to the iron disulfide dissolution. Although the reactions causing oxidation of pyrite and formation of AMD occur in an abiotic environment, lithotrophic microbes can be helpful to accelerate this process (Komnitsas and Pooley, 1990; Mayo et al., 2000; Cheng et al., 2009).

One of the consequences of AMD is the formation of ochre. It has been reported that the term "ochre" is used for materials having iron or iron-rich ore minerals in the range of 3-30\% which are found in the water drainage from coal and other mines (Popelka-Filcoff et al., 2008). The main chromophores responsible for the red and yellow pigments are hematite $\left(\alpha-\mathrm{Fe}_{2} \mathrm{O}_{3}\right)$ and goethite $[\mathrm{FeO}(\mathrm{OH})]$ respectively (Gil et al., 2008). At high $\mathrm{Fe}(\mathrm{III})$ and sulfate concentrations and low $\mathrm{pH}$ jarosite, capable of adsorbing several other heavy metals present in AMD, is formed (Komnitsas et al., 1995).

The objective of the study is to develop a sustainable procedure to extract elemental iron from the naturally prevailing and hazardous ochre. The water in Skelton Beck is regarded as harmful to human and aquatic lives and had been a matter of concern since 1866, the evidence of which can be found in the papers published in "The Lancet" (Rapp et al., 1866). This is the first attempt of its kind to develop a microbial treatment process for the ochre in its natural environment, which will make the procedure more promising and reliable. 


\section{MATERIALS AND METHODS PREPARATION OF OCHRE SAMPLES}

The ochre sample was collected from Skelton Beck river bed, receiving acid mine discharge. Prior to the experiment, the ochre sample was pre-dried in an oven at $40^{\circ} \mathrm{C}$ for $12 \mathrm{~h}$. The dried sample was slowly grinded to obtain fine powder $(<10 \mu \mathrm{m})$, which was then sieved manually with the help of sieve with apertures of $500 \mu \mathrm{m}$ and stored in refrigerator for further use. The Scanning electron microscope (SEM) image of the fresh ochre is presented in Figure 1. Some agglomeration as a result of drying was noticed.

\section{PRE-CULTURE OF THE TWO BACTERIAL STRAINS TO PREPARE BIOMASS FOR INOCULATION}

Anaerobic bacterial strains used were Geobacter sulfurreducens (DSM 12127) and Shewanella denitrificans (DSM 15014). The strains were selected based on their ability to solubilize minerals (Table 1). Sterile nutrient broth (CM0001, Oxoid, UK) was used as medium for G. sulfurreducens (GS) and S. denitrificans (SD). It was prepared with de-ionized water for $G S$ and filtered sea water for $S D$ respectively. Abiotic and biotic controls were maintained for both the cultures. $10 \mathrm{~mL}$ of inoculum ( $48 \mathrm{~h}$ growth) was inoculated in $90 \mathrm{~mL}$ nutrient broth and complete anaerobic condition was maintained in Drechsler bottle by replacing nitrogen gas, which was confirmed with the help of the risazurine anaerobic indicator (BR0055, Oxoid, UK) and 5\% air dried ochre was used in the experiment. Both of the cultures were sub-cultured for $48 \mathrm{~h}$. The bacterial growth was measured using UV visible spectrophotometer (Camspec model: M550) at absorbance of $600 \mathrm{~nm}$.

\section{PREPARATION OF SAMPLES FOR ANALYSIS}

The sub-cultured microorganisms were inoculated in nutrient broth with ochre and were incubated for 8 days in anaerobic condition. The culture was monitored at regular time intervals (2 days) to assess the rate of iron synthesis from ochre by both the strains. For the analysis of solid residues, the culture broth with ochre was transferred to centrifuge tubes. The centrifugation was carried out at $10,000 \mathrm{rpm}$ for $10 \mathrm{~min}$ at $4^{\circ} \mathrm{C}$. Absolute ethanol was added to the pellet thus to sterilize any organisms left and was allowed to dry by placing in the vacuum oven at $64^{\circ} \mathrm{C}$ for $12 \mathrm{~h}$. When the pellet was completely dried, it was homogenized with the help of mortar and pestle until a fine powder was formed, which was then analyzed by X-Ray powder diffraction (XRD), X-Ray fluorescence (XRF), and SEM.

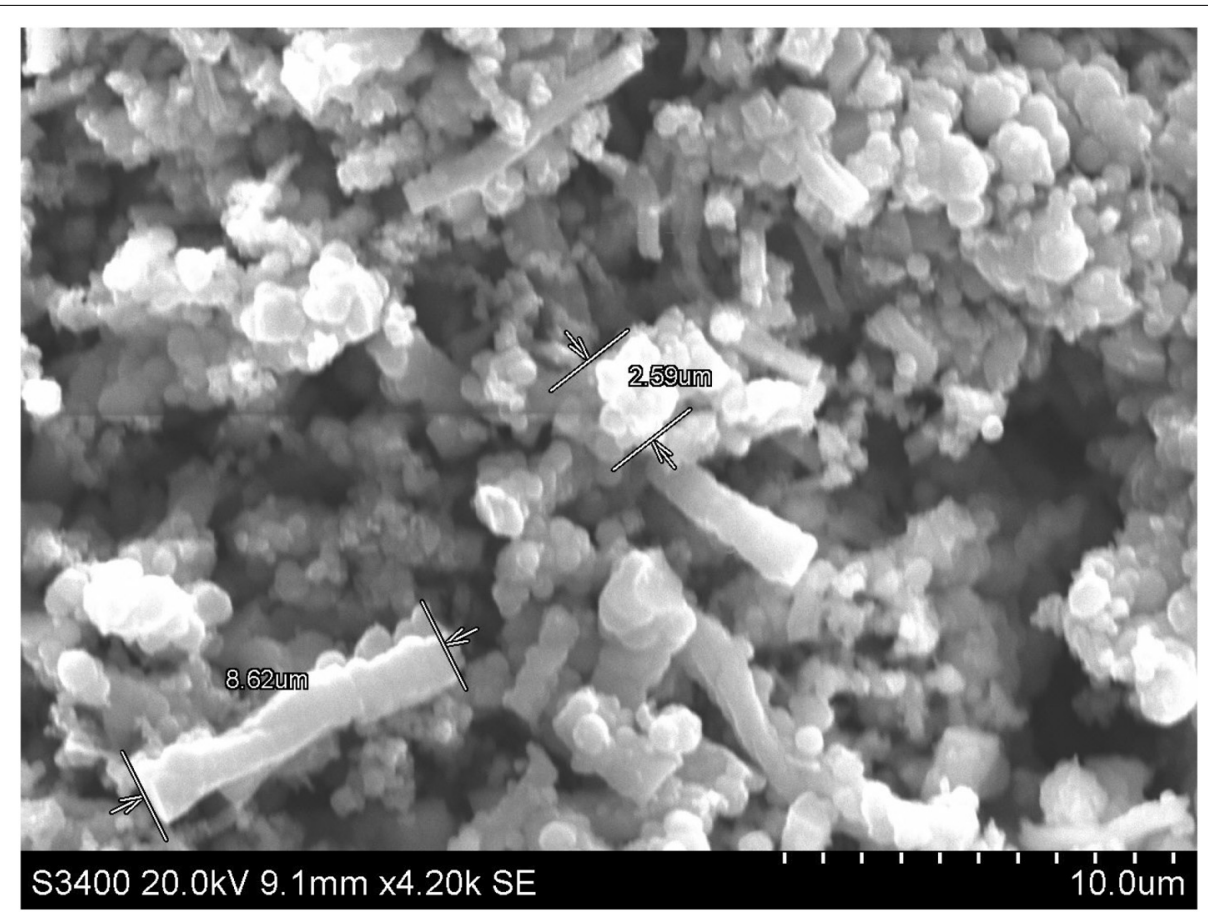

FIGURE 1 | Particle morphology of fresh ochre under scanning electron microscope.

Table 1 | Ability of Geobacter and Shewenella species to solubilize minerals (Kato and Nogi, 2001; Uroz et al., 2009).

\begin{tabular}{|c|c|c|c|c|}
\hline Microorganism & Type of microorganism & Natural Habitat & Mechanism involved & Origin of microorganism \\
\hline Geobacter spp & $\delta$-Proteobacteria & Sub-surface areas & Iron [reduction of Fe(III)] & Sediment \\
\hline Shewenella spp & $\gamma$-Proteobacteria & Deep sea water & $\begin{array}{l}\text { Smectite, } \\
\text { Iron [reduction of Fe(III)], } \\
\text { Calcite, dolomite }\end{array}$ & Anoxic sediment \\
\hline
\end{tabular}




\section{CHEMICAL ANALYSIS (XRF)}

The dried sample was used for the analysis. The XRF analysis was carried out at $30 \mathrm{kV}$ and $150 \mu \mathrm{A}$ using Eagle III Micro-XRF. Vacuum was maintained inside the XRF for the entire sample analysis. The spectrum was collected after 300 scans of $0.5 \mathrm{~mm}$ diameter of the sample.

\section{X-RAY DIFFRACTION ANALYSIS}

The XRD was carried out for all the powdered form of the reduced samples using $\mathrm{Cu} \mathrm{K} \alpha$ target. For each sample, the scanning time was set for $50 \mathrm{~min}$ with graphical axis range from minimum of $2 \theta=20 \circ$ to maximum of $70 \circ$. The peak intensity and the peak position for all the samples after the X-ray scanning were obtained and thus used for identifying the different forms of iron present in the sample.

\section{SEM-EDX ANALYSIS}

The samples were prepared by mounting $10 \mathrm{mg}$ of each reduced sample on aluminum sample holder using double sided tape. These holders were coated with thin film of carbon. Once inside the SEM, random vertical and lateral movements around the microscope stage was carried out to select the appropriate image of the compound present. Then energy dispersive X-ray analysis (EDX) was used to determine the chemical composition of the selected area. The sample was studied by comparing four different spectrums of the area of interest within the sample, to minimize error.

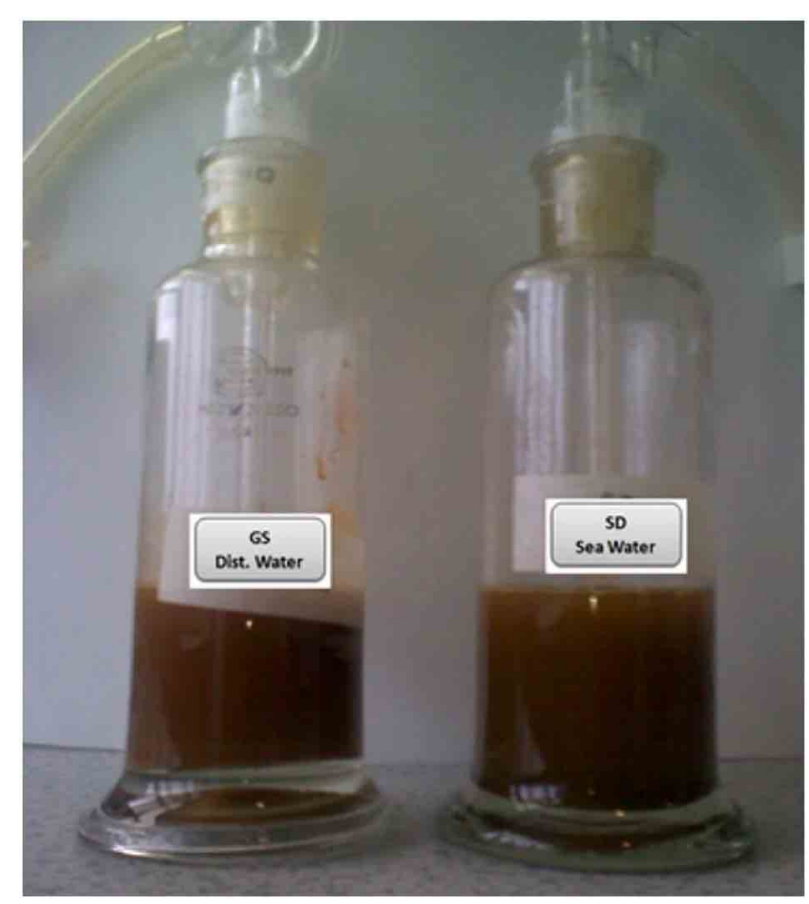

FIGURE 2 | Drechsler bottles showing no distinct color change across all treatments until the second day of incubation. GS, G.

sulfurreducens; SD, S. denitrificans.

\section{RESULTS AND DISCUSSION GROWTH STUDY}

The bacterial growth was monitored using UV visible spectrophotometer at the absorbance of $600 \mathrm{~nm}$. The optical densities of the inocula were 0.927 and 1.753 for GS and for $S D$ respectively. These measurements were used to set-up the experiments.

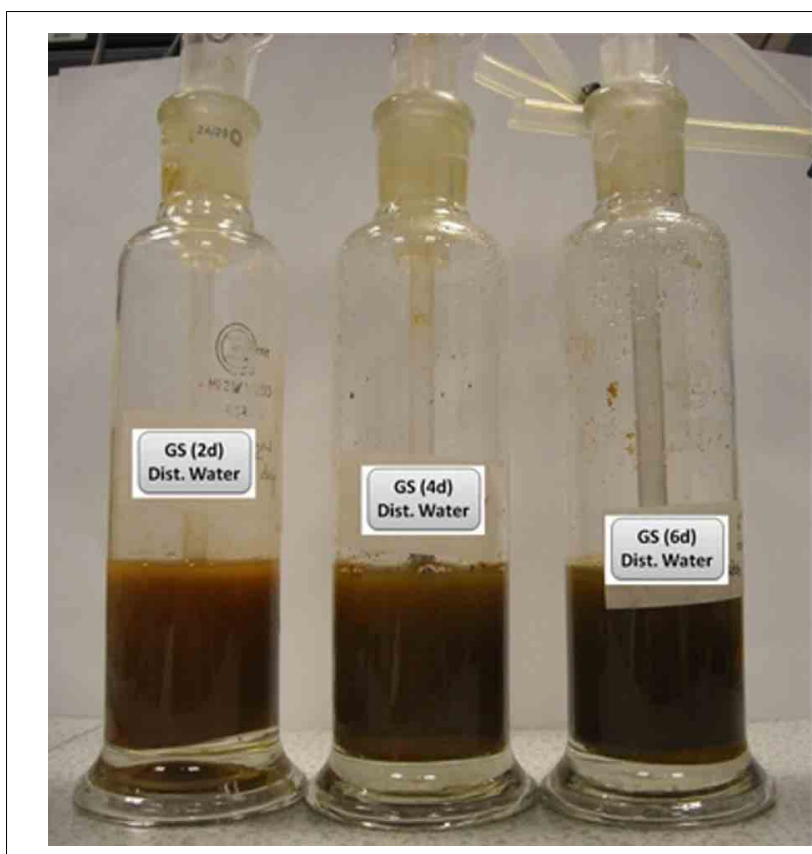

FIGURE 3 | Gradual change in the color of the bottles with increasing incubation period (Inoculated with GS).

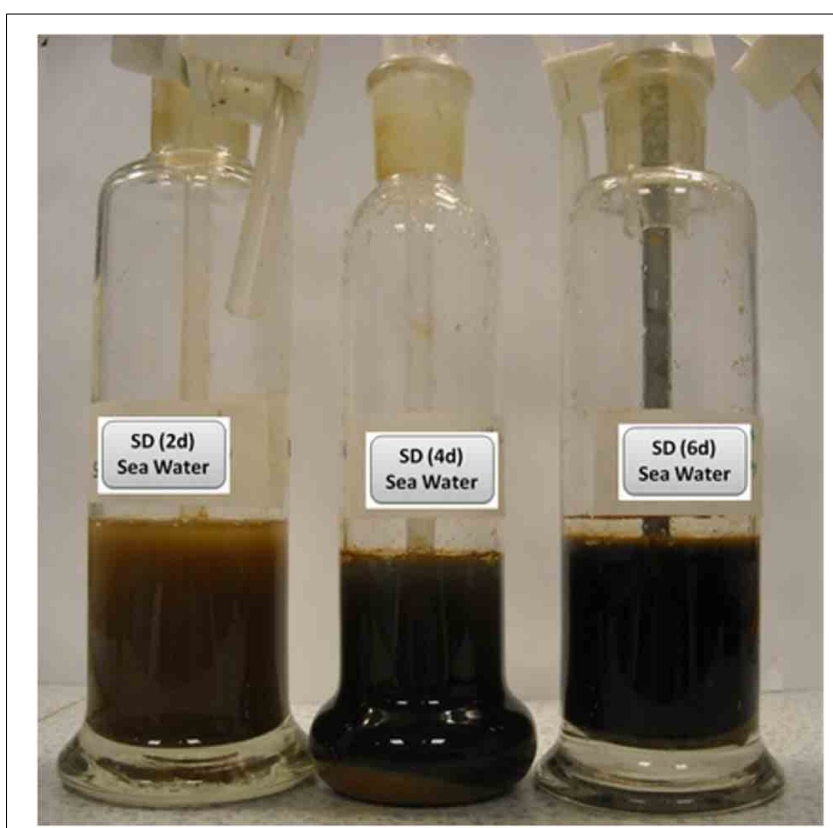

FIGURE 4 | Gradual change in the color of the bottles with increasing incubation period (Inoculated with $S D$ ). 


\section{PHYSICO-CHEMICAL OBSERVATION}

After obtaining complete anaerobic conditions inside the Drechsler bottles, they were incubated at $30^{\circ} \mathrm{C}$ in an incubator. As seen in Figure 2, no distinct change in the color of the samples was observed until the second day of incubation. Then gradual change in the color of the liquid was observed as the incubation time increased (Figure 3 for $G S$ and Figure 4 for $S D$ ). It can clearly be seen from the image that the change in color of the experimental samples inoculated with the $S D$ is more distinct than the samples inoculated with GS. The SD shows distinct black color within the 6 days of incubation whereas the sample inoculated with $G S$ showed only slight change in the color. Close observation showed that the black color particle settled to the bottom of the flask and the liquid showed opaque light black color, however slight shaking of the flask displayed uniform distinct black color. This change in the color could be related to the reduction of the iron oxide present in the ochre to elemental iron. Similar observations were reported earlier. For instance Sun et al. (2006) reported that color of an ochre sample changed to distinct black due to the formation of iron nanoparticles in colloidal form. Furthermore, the bottles incubated for more than 1 week showed a very distinct and dark black color for both the strains. This change in the color was maintained throughout the 8 days possibly due to the absence of any reverse reaction.

The color of the biotic control before incubation was yellow, identical to the ochre color, but as incubation time increased, its color changed gradually to black (Figure 5). This showed that some indigenous microorganisms present in the ochre were able to bring some biotic change in the ochre in the presence of nutrient broth. Acidophilic microorganisms are reported to be found in these types of extreme environment such as the ochre (Johnson, 1998). Moreover, similar change in the color of sample observed only in biotic controls and no change in the abiotic control (Figure 5) proves that the reduction process is completely a biotic process. Absence of color changes in the abiotic control could be due to absence of microorganisms and therefore reduction process could not be initiated and it remained unchanged for the entire 8 days of incubation. Studies have shown that iron oxide is present in all types of ochre. But the variation in their colors can be explained by their composition. Table 2 shows a clear relation between color of ochre and the concentration of iron oxides in the sample (Elias et al., 2006).

\section{EFFECT ON pH}

The $\mathrm{pH}$ of supernatant in the treated samples was found to be 7.8 for GS and 7.2 for $S D$. The $\mathrm{pH}$ of both the strains was noticed to decrease during incubation. A similar effect was observed by Sun et al. (2006). Decrease in pH values were observed after the reduction of ochre to elemental iron, due to the generation of protons. This reduction can be described by the following reaction, illustrating the generation of acidity:

$$
\begin{aligned}
& 4 \mathrm{FeOOH}+\mathrm{CH}_{3} \mathrm{CH}(\mathrm{OH}) \mathrm{COO}^{-} \rightarrow 4 \mathrm{Fe} \\
&+3 \mathrm{HCO}^{3-}+2 \mathrm{H}_{2} \mathrm{O}+2 \mathrm{H}^{+}
\end{aligned}
$$

Table 2 | Relationship between color of ochre and its composition (Elias et al., 2006).

\begin{tabular}{lllc}
\hline Ochre & Presence of hematite & $\begin{array}{l}\text { Presence of } \\
\text { geothite }\end{array}$ & $\begin{array}{c}\text { Variation in } \boldsymbol{\alpha} \\
\text { co-ordinate } \\
\text { (redness) }\end{array}$ \\
\hline Red & Yes $(>80 \%)$ & - & $24.6-43$ \\
Yellow & - & Yes & $4.4-17.3$ \\
Orange & Yes & Yes & $19.5-34.8$ \\
\hline
\end{tabular}

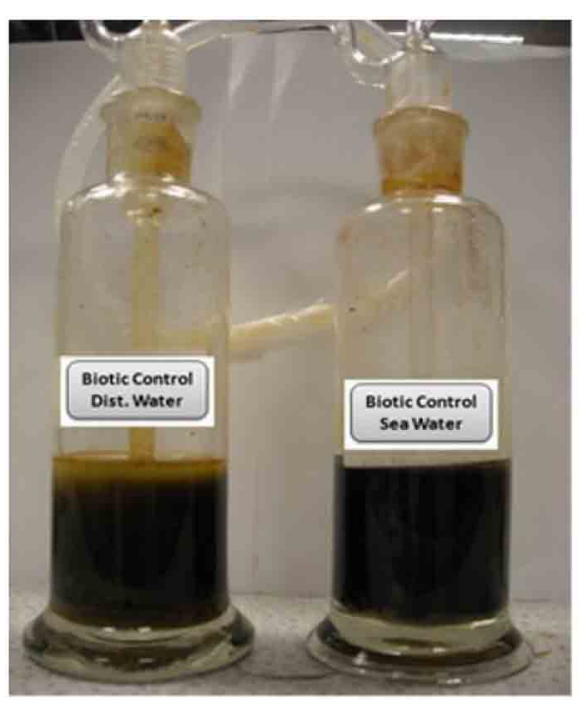

Biotic control

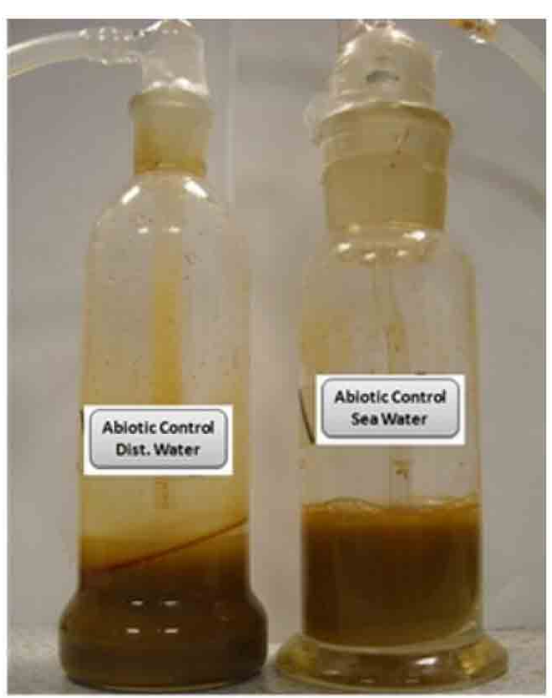

Abiotic control

FIGURE 5 | Biotic and abiotic controls after 8 days of incubation. 

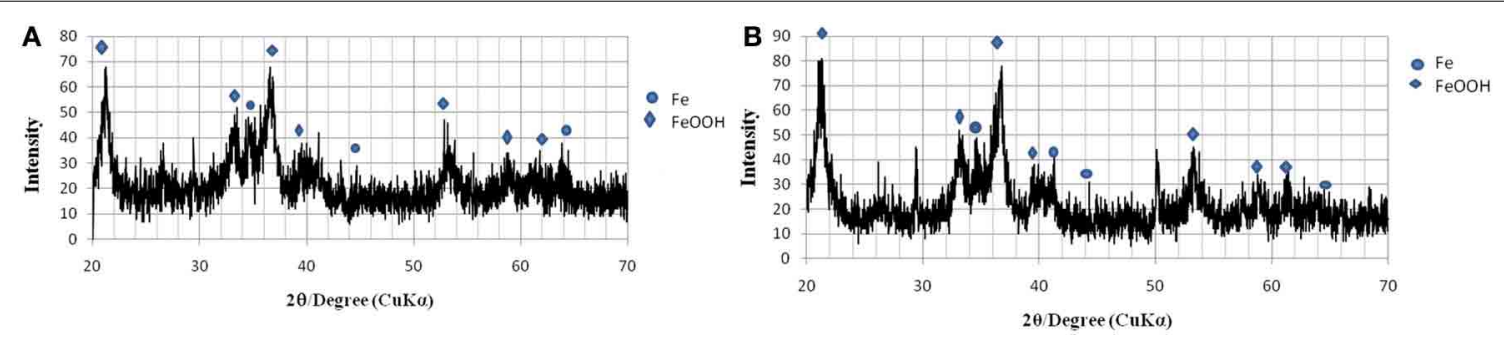

FIGURE 6 | XRD pattern of ochre sample reduced by GS. (A) After 2 days of incubation. (B) After 8 days of incubation.
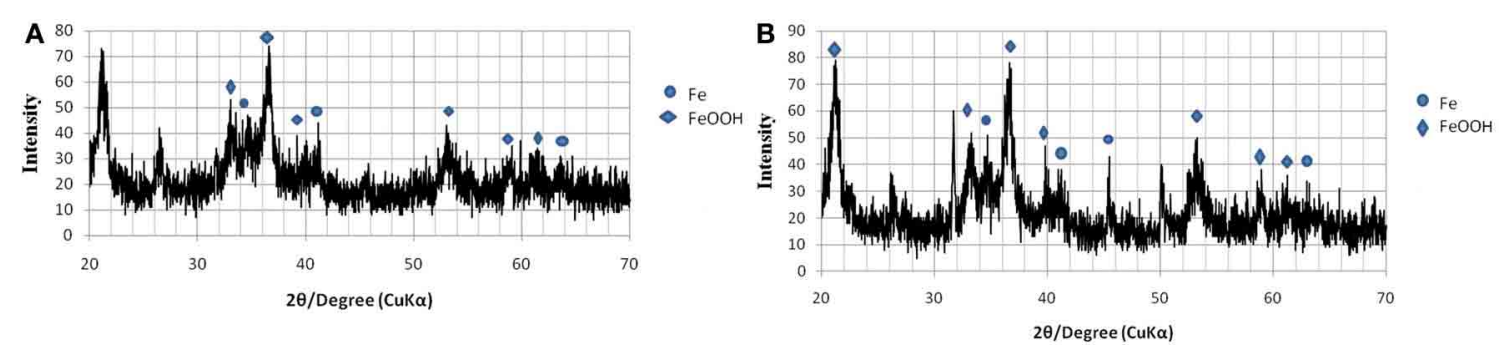

FIGURE 7 | XRD pattern of ochre sample reduced by SD. (A) After 2 days of incubation. (B) After 8 days of incubation.

Table 3 | Elemental composition of ochre samples treated with GS and $S D$ and control samples, as determined using XRF analysis.

\begin{tabular}{lccccc}
\hline Reduced by & Incubation & \multicolumn{5}{c}{ Weight (\%) } \\
\cline { 3 - 6 } & (days) & Fe & Ca & Cl & Si \\
\hline G. sulfurreducens & 2 & 67.38 & 12.73 & 13.45 & 6.44 \\
G. sulfurreducens & 4 & 67.52 & 15.62 & 10.22 & 6.33 \\
G. sulfurreducens & 6 & 69.16 & 13.77 & 11.35 & 5.73 \\
G. sulfurreducens & 8 & 69.16 & 13.77 & 11.35 & 5.73 \\
S. denitrificans & 2 & 65.01 & 12.37 & 15.63 & 6.99 \\
S. denitrificans & 4 & 76.52 & 3.86 & 6.19 & 13.44 \\
S. denitrificans & 6 & 84.74 & 5.65 & 7.63 & 1.98 \\
S. denitrificans & 8 & 84.82 & 5.83 & 7.43 & 1.92 \\
Abiotic control & 8 & 71.73 & - & 28.27 & - \\
(distilled water) & & & & & \\
Abiotic control (sea & 8 & 56.51 & - & 43.49 & - \\
water) & & & & & \\
Biotic control & 8 & 62.82 & 7.60 & 29.59 & - \\
(distilled water) & & & & & \\
Biotic control (sea & 8 & 21.77 & 6.05 & 36.57 & - \\
water) & & & & &
\end{tabular}

\section{XRD PATTERN FOR THE TREATED SAMPLES}

The pattern of peaks of all the samples incubated with GS were similar to some extent but differed in the number of phases for any particular compound. For the sample inoculated with GS (Figures 6A,B) the XRD spectrum indicates some degree of amorphicity in the pattern and also shows the presence of Geothite (iron oxyhydroxide- $\mathrm{FeO}(\mathrm{OH})$. The phase of the goethite found was the hydrated goethite. Previous studies have
Table 4 | Results of EDX-SEM analyses for the ochre sample treated with GS.

\begin{tabular}{ccrcccccc}
\hline Spectrum & In stats. & $\mathbf{C}$ & $\mathbf{S i}$ & $\mathbf{C l}$ & $\mathbf{C a}$ & $\mathbf{F e}$ & $\mathbf{O}$ & Total \\
\hline 1 & Yes & 13.82 & 1.03 & 0.23 & 1.35 & 35.01 & 48.56 & 100.00 \\
2 & Yes & 14.02 & 0.90 & 0.36 & 1.21 & 34.72 & 48.80 & 100.00 \\
3 & Yes & 14.41 & 0.77 & 0.37 & 1.23 & 33.79 & 49.43 & 100.00 \\
4 & Yes & 12.88 & 0.84 & 0.19 & 1.45 & 37.92 & 46.71 & 100.00 \\
Mean & & 13.78 & 0.88 & 0.29 & 1.31 & 35.36 & 48.38 & 100.00 \\
Std. Dev. & & 0.65 & 0.11 & 0.09 & 0.11 & 1.79 & 1.17 & \\
Max. & & 14.41 & 1.03 & 0.37 & 1.45 & 37.92 & 49.43 & \\
Min. & & 12.88 & 0.77 & 0.19 & 1.21 & 33.79 & 46.71 & \\
& & & & & & & &
\end{tabular}

demonstrated that at certain conditions amorphous iron(III) hydroxide are transformed to crystalline iron oxides and oxyhydroxides, such as $\alpha-\mathrm{Fe}_{2} \mathrm{O}_{3}$ and $\alpha-\mathrm{FeOOH}$ (Krehula and Music, 2008).

From the XRD spectra presented in Figures 6, 7, it can be observed that all the samples contain goethite $(\alpha-\mathrm{FeOOH})$ as major iron phase and elemental iron, FeO, as a secondary crystalline phase. The variation in the intensity of peaks can be related to the total incubation period of the samples, and the type of the microbial strain inoculated. A distinct peak with very high intensity was observed in all the samples inoculated with $S D$, but it was not present in the XRD pattern of the samples inoculated with $G S$. This distinct peak was observed at about $2 \theta=31.90 \circ$, which does not fall under any type of iron oxides, but it can be attributed to the mineral siderite, $\mathrm{FeCO}_{3}$, which is a usual bioreduction product of iron hydroxides (Fredrikson et al., 1998). The patterns of peaks for all the samples inoculated with $S D$ are found to be rather identical to each other, though they differ in intensity. The sample 
inoculated with $S D$ (Figures 7A,B) show distinctly different peaks than those obtained from GS.

\section{XRF ANALYSIS OF TREATED SAMPLES}

The XRF analysis was carried out for all the samples including four controls. Quantitative results obtained from the XRF analyses further confirm the presence of relatively high percentage of iron. Along with iron, other elements present were silicon, chloride and calcium. The net weight and atomic percentages are summarized in Table 3. Even though the type of elements present in all the samples was similar, they show some variations in their weight percentage. This variation in their percentage weight was

Table 5 | Results of EDX-SEM analyses for the ochre sample treated with SD.

\begin{tabular}{|c|c|c|c|c|c|c|c|c|c|c|}
\hline Spectrum & In stats. & $\mathrm{Na}$ & $\mathbf{M g}$ & Si & $\mathbf{S}$ & $\mathrm{Cl}$ & $\mathrm{Ca}$ & $\mathrm{Fe}$ & 0 & Total \\
\hline 1 & Yes & 1.14 & 0.81 & 1.54 & 0.34 & 2.19 & 2.00 & 68.40 & 23.59 & 100.00 \\
\hline 2 & Yes & 1.20 & 0.78 & 1.40 & 0.43 & 2.18 & 2.02 & 68.41 & 23.58 & 100.00 \\
\hline 3 & Yes & 1.12 & 0.84 & 1.44 & 0.47 & 2.14 & 2.06 & 68.26 & 23.67 & 100.00 \\
\hline 4 & Yes & 1.12 & 0.85 & 1.48 & 0.36 & 2.23 & 2.02 & 68.37 & 23.57 & 100.00 \\
\hline Mean & & 1.14 & 0.82 & 1.46 & 0.40 & 2.18 & 2.03 & 68.36 & 23.60 & 100.00 \\
\hline Std. deviation & & 0.04 & 0.03 & 0.06 & 0.06 & 0.04 & 0.02 & 0.07 & 0.05 & \\
\hline Max. & & 14.41 & 1.03 & 0.37 & 1.45 & 37.92 & 49.43 & & & \\
\hline Min. & & 12.88 & 0.77 & 0.19 & 1.21 & 33.79 & 46.71 & & & \\
\hline
\end{tabular}
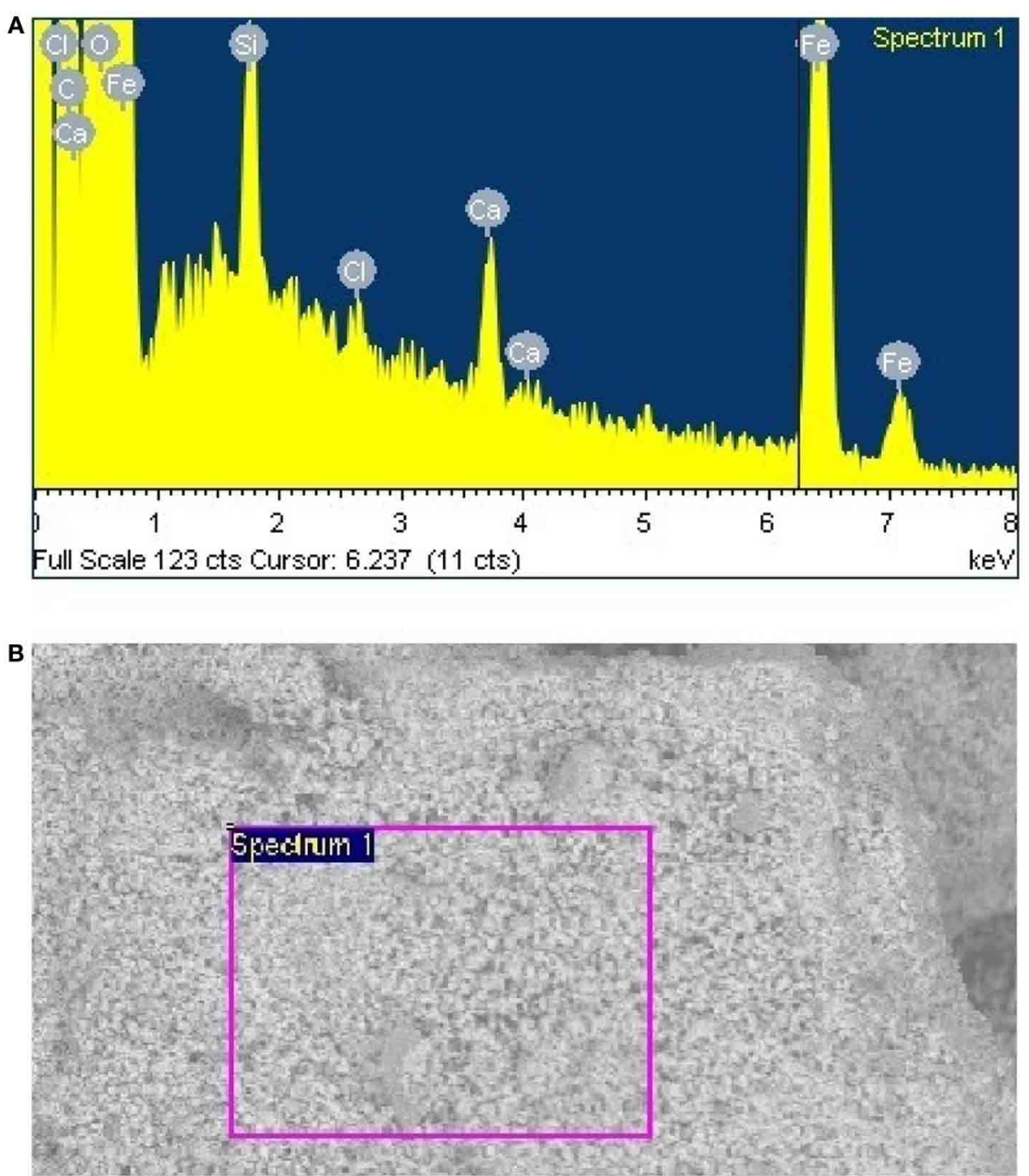

FIGURE 8 | (A) Site of observation for the samples from GS treatment (B) Elemental analysis data obtained from spectrum one. 
found to be affected by the length of incubation time for each sample. However the percentage of iron gradually increases as the length of incubation time increases. The iron percentage reached from 67 to $69 \%$ for $G S$ and 65 to 84 for $S D$ within the first week of incubation. As the color of sample inoculated with $S D$ changed much faster than the sample inoculated with GS, it can be said that $S D$ is much more effective and efficient in the reduction process.

\section{MINERALOGICAL ANALYSIS USING SCANNING ELECTRON MICROSCOPE (SEM)}

The GS treated sample was analyzed by EDX in SEM. Four different EDX spectra were recorded and the results are presented in Table 4. The main elements were iron (35.4\%), oxygen $(48.4 \%)$, carbon $(13.8 \%)$, silicon $(0.88 \%)$, and calcium $(1.31 \%)$. Four different EDX spectra were also recorded for the sample treated by $S D$ (Table 5). In addition to $\mathrm{Fe}, \mathrm{O}, \mathrm{Ca}, \mathrm{Si}$, and $\mathrm{Cl}$, the sample also contained $\mathrm{Na}, \mathrm{Mg}$, and $\mathrm{S}$. The presence of sodium could have been due to the use of sea water in the preparation of nutrient broth for $S D$. However the percentage by weight of sodium, Magnesium, and sulfur is almost negligible as they were just $1.14,0.82$, and $0.04 \%$ weight respectively. Moreover the sample reduced by $S D$ was found to have higher iron percentage $(68.36 \%)$ than sample reduced by $G S(35.36 \%)$. Site of observation for the first spectrum of $S D \& G S$ and the elements obtained from the spectrum are presented in Figures 8, 9.

\section{CONCLUSION}

The physio-chemical observation showed that iron oxide can be reduced from ochre by anaerobic bacterial strains namely $G S$ and SD. The efficiency of the reduction process and the rate of reduction with increasing incubation period were examined. The changes in sample color from orange to black showed that microbial activities have induced the reduction process. Reduction residues were analyzed using XRD, XRF, and SEM. Examination of samples by XRD revealed the presence of elemental iron and geothite. XRD data also proved that the peak intensity of geothite, as well as of elemental iron, increased with the increase in incubation period. Moreover, the observation of the change in color of the samples showed

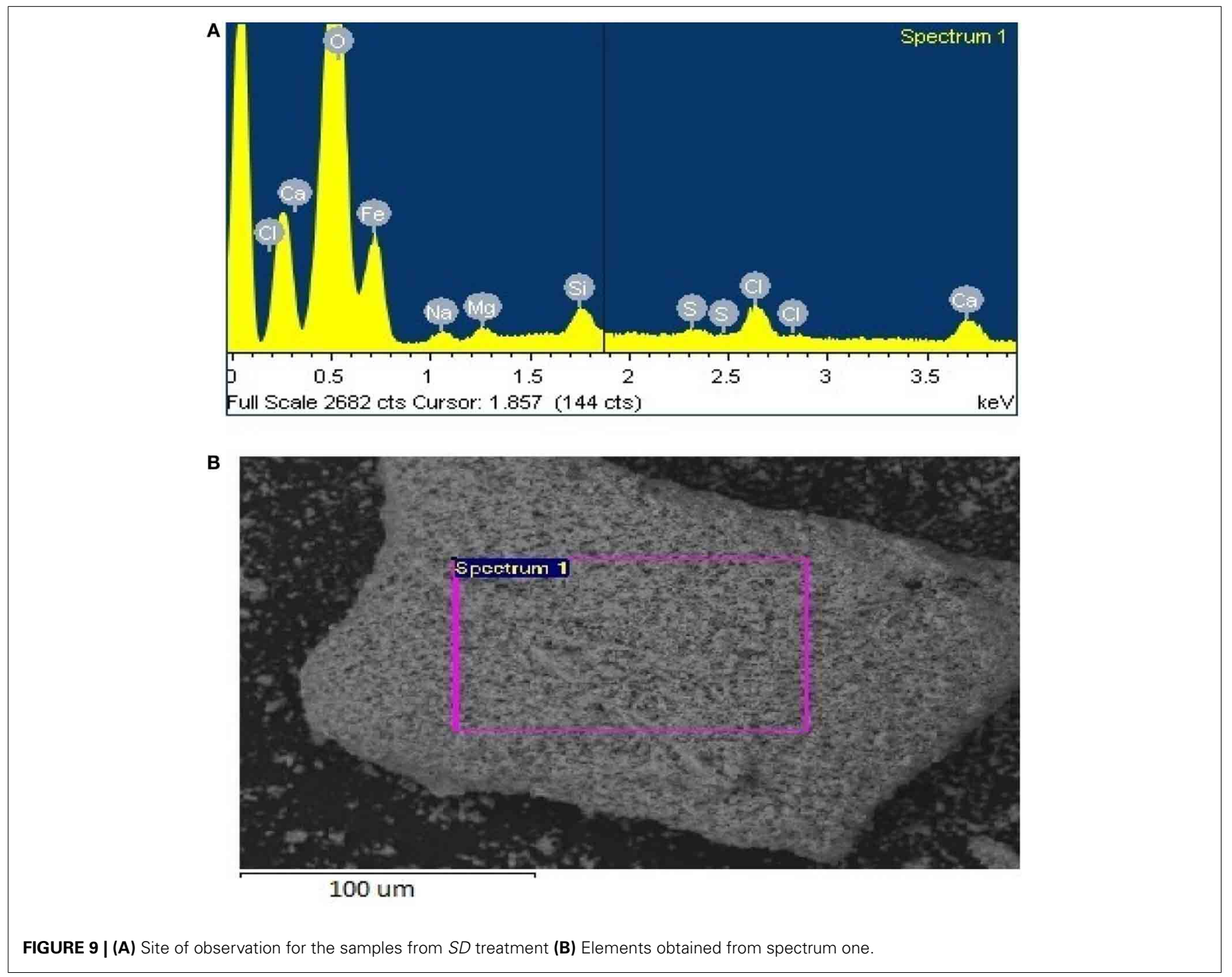


that the reduction process is much faster in case of $S D$ in comparison to GS.

\section{ACKNOWLEDGMENT}

Authors wish to thank the Dean, School of Science and Engineering for providing facilities, Dr. Sayed El-Ghaith and Ms. Aparna J. Padman for their assistance in the laboratory works.

\section{REFERENCES}

Cheng, H., Hu, Y., Luo, J., Xu, B., and Zhao, J. (2009). Geochemical processes controlling fate and transport of arsenic in acid mine drainage (AMD) and natural systems. J. Hazard. Mater. 165, 13-26. doi: 10.1016/j.jhazmat.2008.10.070

Elias, M., Chartier, C., Prévot, G., Garay, H., and Vignaud, C. (2006). The colour of ochres explained by their composition. Mater. Sci. Eng. 127, 70-80. doi: 10.1016/j.mseb.2005.09.061

Engleman, C. J. Jr., and McDiffett, W. F. (1996). Accumulation of aluminum and iron by bryophytes in streams affected by acid-mine drainage. Environ. Pollut. 94, 67-74. doi: 10.1016/S0269-7491(96)00055-3

Fredrikson, J. K., Zachara, J. M., Kennedy, D. W., Dong, H. Onstott, T. C., Hinman, N. W., and Shu-Mei L. (1998). Biogenic iron mineralization accompanying the dissimilatory reduction of hydrous ferric oxide by a groundwater bacterium, Geochim Cosmochim AC. 62, 3239-3257. doi: 10.1016/S0016-7037(98)00243-9

Gil, M., Carvalho, M. L., Seruya, A., Candeias, A. E., Mirão, J., and Queralt, I. (2008). Yellow and red ochre pigments from southern Portugal: Elemental composition and characterization by WDXRF and XRD. Nuclear Inst. Methods Phys. Res. A 580, 728-731. doi: 10.1016/j.nima.2007.05.131

Johnson, D. B. (1998). Biodiversity and ecology of acidophilic microorganisms. FEMS Microbiol. Ecol. 27, 307-317. doi: 10.1111/j.1574-6941.1998.tb00547.x

Kato, C., and Nogi, Y. (2001). Correlation between phylogenetic structure and function: examples from deep-sea Shewanella. FEMS Microbiol. Ecol. 35, 223-230. doi: 10.1111/j.1574-6941.2001.tb00807.x

Komnitsas, C., and Pooley, F. D. (1990). Bacterial oxidation of a refractory gold sulphide concentrate from Olympias, Greece. Miner. Eng. 3, 295-306, doi: 10.1016/0892-6875(90)90125-U

Komnitsas, K., Xenidis, A., and Adam, K. (1995). Oxidation of pyrite and arsenopyrite in sulphidic spoils in Lavrion. Miner. Eng. 8, 1443-1454. doi: 10.1016/08926875(95)00109-3

Krehula, S., and Music, S. (2008). Influence of cobalt ion in precipitation of goethite in highly alkaline media. Clay Miner. 43, 95-105. doi: 10.1180/claymin.2008.043.1.07

Mayes, W. M., Johnston, D., Potter, H. A. B., and Jarvis, A. P. (2009). A national strategy for identification, prioritisation and management of pollution from abandoned non-coal mine sites in England and Wales. I.: Methodology development and initial results. Sci. Total Environ. 407, 5435-5447. doi: 10.1016/j.scitotenv.2009.06.019

Mayo, A. L., Petersen, E. C., and Kravits, C. (2000). Chemical evolution of coal mine drainage in a non-acid producing environment, Wasatch Plateau, Utah, USA. J. Hydrol. 236, 1-16. doi: 10.1016/S0022-1694(00)00277-8

Mohan, D., and Chander, S. (2006). Removal and recovery of metal ions from acid mine drainage using lignite - A low cost sorbent. J. Hazard. Mater. 137, 1545-1553. doi: 10.1016/j.jhazmat.2006.04.053

Popelka-Filcoff, R. S., Miksa, E. J., Robertson, J. D., Glascock, M. D., and Wallace, H. (2008). Elemental analysis and characterization of ochre sources from Southern Arizona. J. Archaeol. Sci. 35, 752-762. doi: 10.1016/j.jas.2007.05.018

Rapp, W., Taylor, W., and Cunningham, J. (1866). The sanitary condition of Salt burn. Lancet 88, 505-506

Sheoran, A. S., and Sheoran, V. (2006). Heavy metal removal mechanism of acid mine drainage in wetlands: a critical review. Miner. Eng. 19, 105-116. doi: 10.1016/j.mineng.2005.08.006

Simpson, S. L., Vardanega, C. R., Jarolimek, C., Jolley, D. F., Angel, B. M., and Mosley, L. M. (2014). Metal speciation and potential bioavailability changes during discharge and neutralisation of acidic drainage water. Chemosphere 103, 172-180, doi: 10.1016/j.chemosphere.2013.11.059

Sun, Y., Li, X., Cao, J., Zhang, W., and Wang, H. P. (2006). Characterization of zero-valent iron nanoparticles. Adv. Colloid Interface Sci. 120, 47-56. doi: 10.1016/j.cis.2006.03.001

Uroz, S., Calvaruso, C., Turpault, M., and Frey-Klett, P. (2009). Mineral weathering by bacteria: ecology, actors and mechanisms. Trends Microbiol. 17, 378-387. doi: 10.1016/j.tim.2009.05.004

Conflict of Interest Statement: The authors declare that the research was conducted in the absence of any commercial or financial relationships that could be construed as a potential conflict of interest.

Received: 02 April 2014; accepted: 01 June 2014; published online: 17 June 2014.

Citation: Rahman PKSM and Bastola S (2014) Biological reduction of iron to the elemental state from ochre deposits of Skelton Beck in Northeast England. Front. Environ. Sci. 2:22. doi: 10.3389/fenvs.2014.00022

This article was submitted to Wastewater Management, a section of the journal Frontiers in Environmental Science.

Copyright (c) 2014 Rahman and Bastola. This is an open-access article distributed under the terms of the Creative Commons Attribution License (CC BY). The use, distribution or reproduction in other forums is permitted, provided the original author(s) or licensor are credited and that the original publication in this journal is cited, in accordance with accepted academic practice. No use, distribution or reproduction is permitted which does not comply with these terms. 